\title{
Вольт-амперные характеристики композитных графен-нанотрубных пленок с нерегулярным расположением нанотрубок
}

\author{
(C) О.Е. Глухова, М.М. Слепченков, В.В. Митрофанов, П.В. Барков \\ Саратовский национальный исследовательский государственный университет им. Н.Г. Чернышевского, \\ 410012 Саратов, Россия \\ ฯ E-mail: barkovssu@mail.ru
}

Поступила в Редакцию 29 мая 2019 г.

В окончательной редакции 8 июля 2019 г.

Принята к публикации 10 июля 2019 г.

\begin{abstract}
Построены топологические модели композитных пленок графен/УНТ, которые представляют собой трубки, лежащие нерегулярно между монослоями графена, параллельно им, ковалентно связанные с графеном. Расстояние между трубками измерялось в гексагонах $\left(\mathrm{H}_{1} \mathrm{l}_{2} \mathrm{H}_{2}\right)$ графена между ребрами, участвующими в образовании ковалентных связей. Было показано, что энергетически устойчивыми являются только те пленки, которые основываются на трубках типа zigzag (n.0) с четным числом $n$. Самой стабильной структурой, согласно нашим исследованиям, является пленка с трубкой (10.0) и с шагом расположения 6/8. Обнаружено, что энергетическая щель присутствует в зонной структуре всех исследованных моделей пленок и составляет величину в интервале $0.41-0.73$ эВ.
\end{abstract}

Ключевые слова: вольт-амперные характеристики, композитные пленки, графен, углеродные нанотрубки, компьютерное моделирование.

DOI: 10.21883/FTP.2019.12.48628.9175

\section{1. Введение}

Композитные пленки графен/углеродные нанотрубки (УНТ) являются одним из перспективных наноматериалов. Гибридные композитные пленки представляют собой трубки, лежащие между монослоями графена, параллельно им, ковалентно связанные с графеном или ван-дер-ваальсово. Среди них в свою очередь выделяются структуры с параллельным расположением УНТ по отношению друг к другу, шахматным и хаотичным. Существует несколько способов получения таких пленок. Например, в работе [1] было продемонстрировано изготовление тонких композитных пленок на основе графена, ковалентно связанного с УНТ, реализованное путем отжига подложек из меди, покрытых додецилфункционализированными УНТ. В работе [2] гибридная графеновая пленка была синтезирована аналогичным способом, при котором графен выращивался с использованием термического CVD метода (TCVD) на медной фольге, покрытой нанотрубками. Для уменьшения контактного сопротивления между графеном и нанотрубками трубки были предварительно нанесены методом центрифугирования на медную фольгу, а затем пленки графена были синтезированы на подложке $\mathrm{YHT} / \mathrm{Cu}$ с использованием TCVD для получения гибридных пленок. Следует также отметить, что композитные пленки графен/УНТ могут выращиваться на различных подложках путем химического восстановления функционализированных кислородными группами нанотрубок и оксида графена при низкой температуре. Однако такой гибридный материал характеризуется слабой связью графен-УНТ и наличием дефектов, возникающих в процессе синтеза [3]. Физические свойства композитных пленок графен/УНТ активно изучаются в настоящее время. Наиболее хорошо исследованы удельная емкость и фотокондуктивность. Установлено, что удельная емкость подобной композитной пленки сильно зависит от массового соотношения между оксидом графена и нанотрубками [4]. При содержании УНТ от $20 \%$ композитные пленки графен/УНТ демонстрируют удельную емкость 206 Ф/Г в 1-этил-3-метилимидазолия тетрафторборатном электролите. Также установлено, что поры композитных пленок, размеры которых превышают в 2 раза размер ионов электролита, преимущественно и определяют величину удельной емкости. В работе [5] было показано, что композитные пленки графен/УНТ способны накапливать электрохимическую энергию, когда он применяется в качестве активного материала, нанесенного на электрод. Полученный таким образом композитный электрод характеризуется удельной емкостью 279.4 Ф/г. Также композитные пленки графен/УНТ демонстрируют высокую фотокондуктивную эффективность, обеспечивая $\sim 10^{5}$ электронов на один поглощенный фотон. На основе таких пленок изготавливается широкополосный фотоприемник (400-1550 нм) с высокой фоточувствительностью, превышающей $100 \mathrm{~A} \cdot \mathrm{BT}^{-1}$, и малым временем отклика $\sim 100$ мкс [6]. Однако, несмотря на широкие исследования свойств композитных пленок графен/УНТ, об электропроводности этого материала практически ничего неизвестно.

В данной работе теоретическими методами исследованы закономерности электропроводности пленок графен/УНТ, которые представляют собой два монослоя графена с однослойными УНТ, расположенными между ними и соединенными с ними ковалентными связями. 


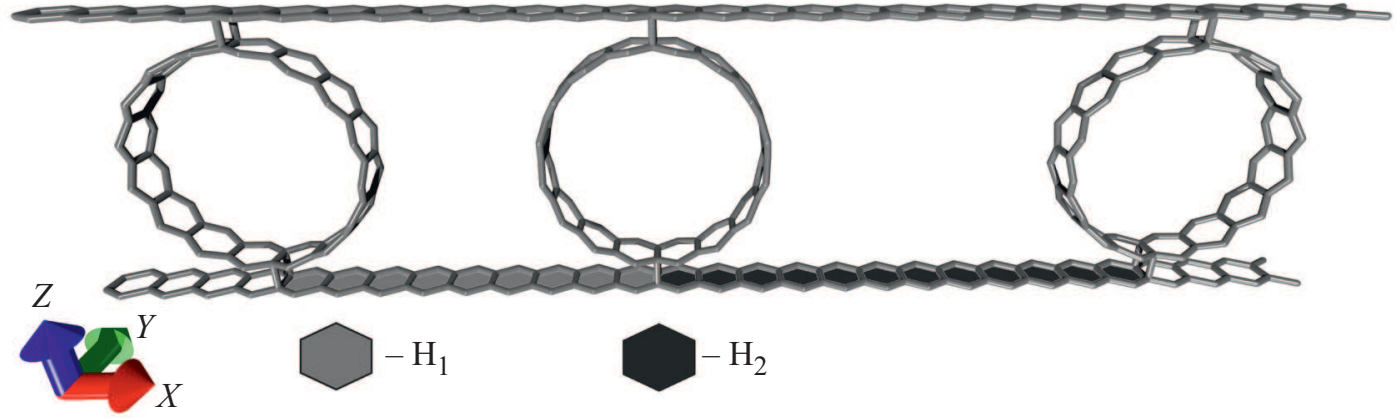

Рис. 1. Фрагмент композитной пленки графен/УНТ на основе трубки (16.0) с шагом $\mathrm{H}_{1}=9$ и $\mathrm{H}_{2}=12$.

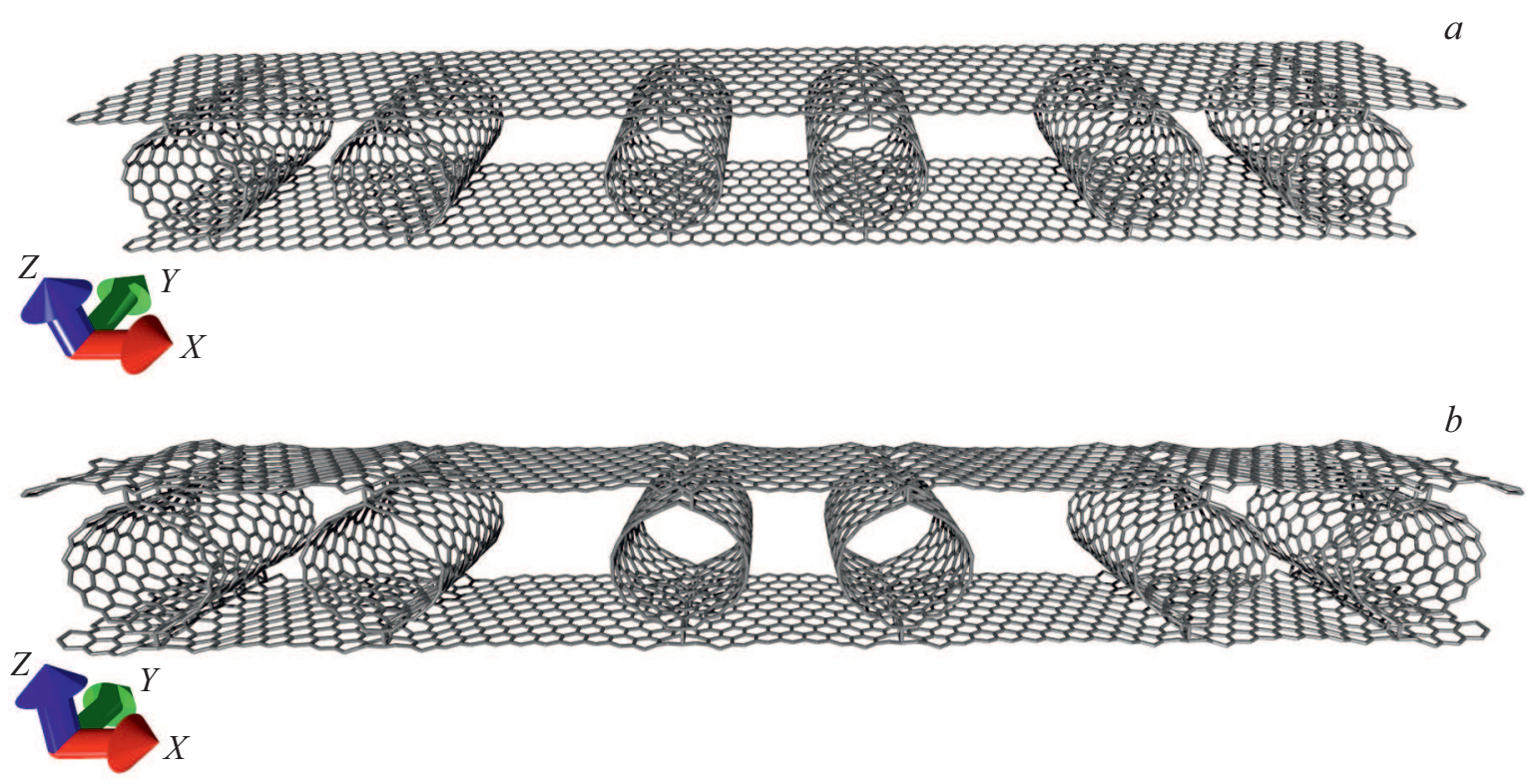

Рис. 2. Модель фрагмента композитной пленки графен/УНТ на основе трубки (16.0) с шагом $\mathrm{H}_{1}=9$ и $\mathrm{H}_{2}=12: a-$ до оптимизации; $b$ - после оптимизации эмпирическим методом AIREBO.

Трубки располагаются с нерегулярным шагом, параллельно друг другу.

\section{2. Атомистические модели и энергетические характеристики}

Ранее авторами были построены атомистические модели и исследована динамическая проводимость композитных пленок графен/УНТ с регулярным расположением нанотрубок [7]. Было показано, что энергетически выгодными являются только те пленки, которые основываются на трубках типа zigzag $(n, 0)$. В таких пленках образуется ковалентная связь графен-УНТ длиной связи $\sim 1.6 \AA$. В данной работе рассматривается слой параллельных друг другу трубок типа zigzag $(n, 0)$, заключенных между двумя монослоями графена и соединенных с ними ковалентными связями, но расположенных нерегулярно, как показано на рис. 1. Рассмотрены нанотрубки с $n=10-16$ ( $n$ изменяется с шагом 1$)$. Расстояние между трубками измерялось в гексагонах
$\left(\mathrm{H}_{1}\right.$ и $\left.\mathrm{H}_{2}\right)$ графена между ребрами, участвующими в образовании ковалентных связей (рис. 1). Расстояние $\mathrm{H}_{1}$ определялось минимальным расстоянием между нанотрубками, при котором структура композита не разрушалась. Расстояние $\mathrm{H}_{1}$ во всех случаях было меньше расстояния $\mathrm{H}_{2}$, при этом количество гексагонов $\mathrm{H}_{1}$ варьировалось в пределах 6-9, а количество $\mathrm{H}_{2}$ в пределах 7-14, со всеми возможными сочетаниями $\mathrm{H}_{1} / \mathrm{H}_{2}$. Шаг $\mathrm{H}_{2}=\mathrm{H}_{1}+k$ ( $k$ изменялось в пределах $1-5$ с шагом 1$)$.

Как и в работе [7], здесь был применен оригинальный, разработанный авторами, „метод лупы“ для построения суперьячеек композитных пленок. Его суть кратко заключается в следующем. 1) Сначала строится большой фрагмент композитной пленки, включающий несколько нанотрубок, как показано на рис. 2, $a$. К нему применяются эмпирическая модель AIREBO [8] и метод молекулярной динамики для оптимизации атомного каркаса (рис. $2, b)$. На этом этапе количество атомов в структуре достигает 3288-4460 атомов, поэтому оптимизация может быть реализована только с применением 


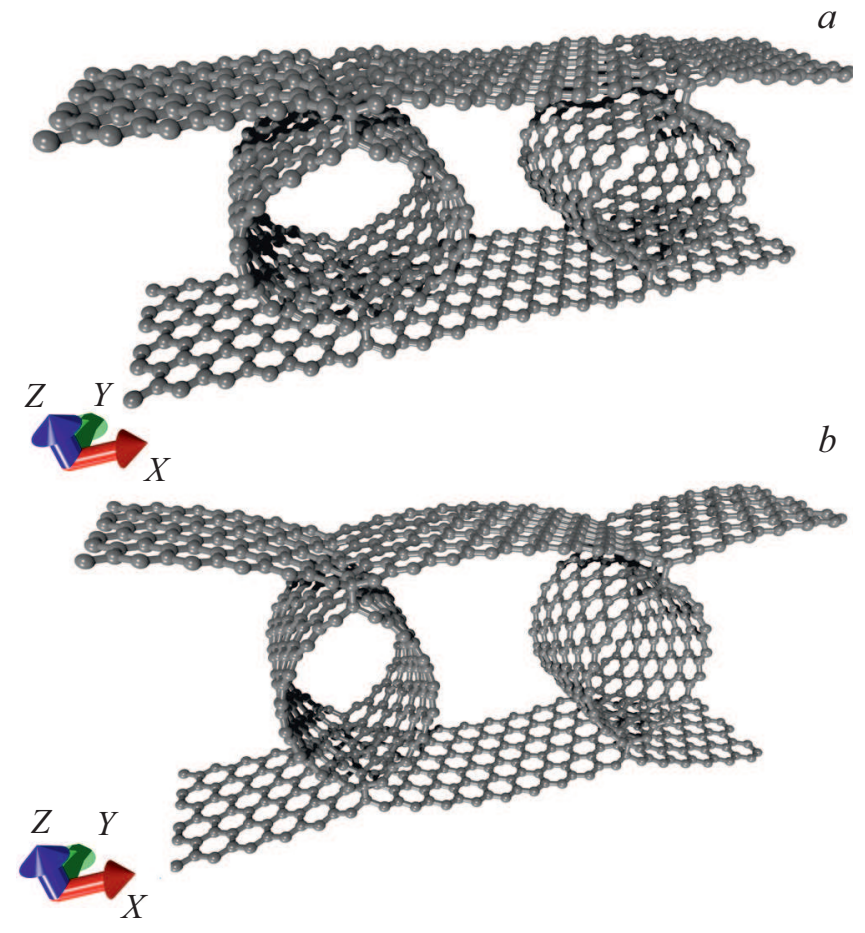

Рис. 3. Серединная часть фрагмента композитной пленки графен/УНТ: $a$ - до оптимизации квантовым методом SCC DFTB2, $b$ - после оптимизации методом SCC DFTB2.

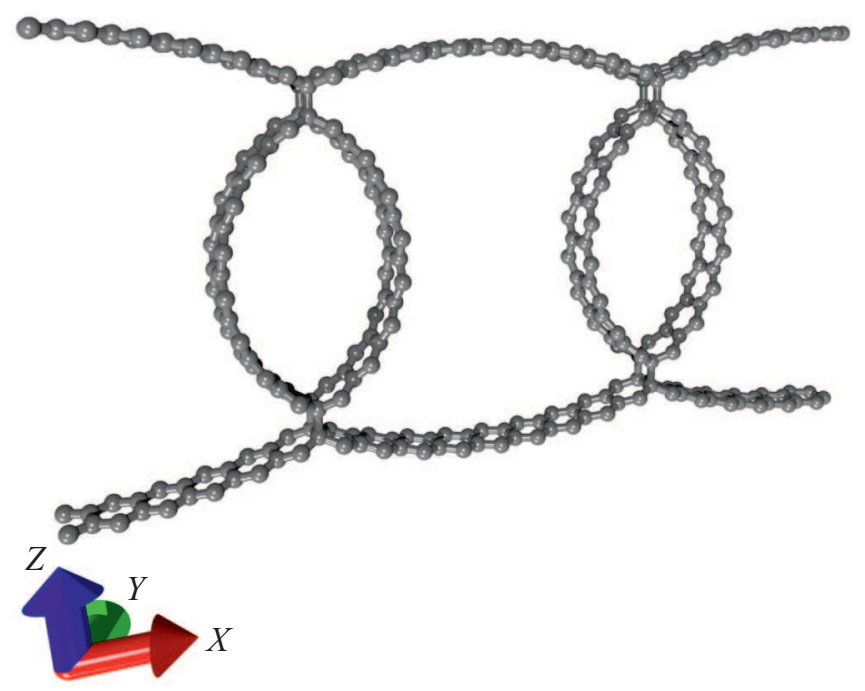

Рис. 4. Модель суперьячейки композитной пленки графен/УНТ на основе трубки (16.0) с шагом $\mathrm{H}_{1}=9$ и $\mathrm{H}_{2}=12$.

эмпирической модели. 2) Затем „вырезается“ из оптимизированного большого фрагмента малая серединная часть, как на рис. 3, $a$, для реоптимизации которой уже применяется квантовый метод. В данной работе применялся метод SCC DFTB2 $[9,10]$. На этом этапе вводятся векторы трансляций $L_{x}, L_{y}$ вдоль направлений $X$ и $Y$ соответственно. Поэтому реоптимизация осуществляется в виде двойной оптимизации периодиче- ского ящика и атомов его структуры. Это подразумевает пошаговое изменение длин векторов трансляций $\mathrm{L}_{x}$, $L_{y}$ с оптимизацией атомного каркаса периодического ящика, построенного на базе этих $L_{x}, L_{y}$. В итоге получается набор минимальных значений энергии для каждого набора $L_{x}, L_{y}$, из которого уже и определяется глобальный минимум энергии. Результаты реоптимизации методом SCC DFTB2 показаны на рис. 3, b. 3) На последнем этапе „вырезается“ из оптимизированного методом SCC DFTB2 периодического фрагмента окончательная суперьячейка, пример которой показан на рис. 4, где изображена суперъячейка с нанотрубками (16.0) диаметром 1.2 нм с шагом 9/12.

В итоге были построены атомистические модели суперьячеек с трубками диаметром 0.8-1.2 нм с различными расстояниями $\mathrm{H}_{1} / \mathrm{H}_{2}$. Длина ковалентной связи графен-УНТ составила $\sim 1.61-1.63 \AA$. Наши исследования показали, что энергетически устойчивые соединения графен-УНТ с ковалентными связями могут образовывать только трубки типа zigzag (n.0) с четным числом $n$. Термодинамическая стабильность построенных атомистических моделей композитных пленок проверялась по величине теплоты образования $\Delta \mathrm{H}_{f}$ композита из графена и нанотрубок. В таблице приведены значения $\Delta \mathrm{H}_{f}$ для различных топологических моделей композитных пленок. Из таблицы видно, что с увеличением диаметра УНТ значение $\Delta \mathrm{H}_{f}$ увеличивается и приближается к нулю в отдельных случаях. Теплота образования, близкая к нулевой, свидетельствует о возможной

Геометрические и энергетические характеристики композитных пленок

\begin{tabular}{c|c|c|c|c|c|c}
\hline Параметры & $\mathrm{H}_{1} / \mathrm{H}_{2}$ & $\begin{array}{c}L_{x}, \\
\AA\end{array}$ & $\begin{array}{c}L_{y}, \\
\AA\end{array}$ & $\begin{array}{c}\Delta \mathrm{H}_{f}, \\
\text { ккал/моль } \cdot \text { атом }\end{array}$ & $\begin{array}{c}E_{f}, \\
\text { эВ }\end{array}$ & $\begin{array}{c}E_{\text {gap }}, \\
\text { эB }\end{array}$ \\
\hline$(10.0)$ & $6 / 7$ & 32.07 & 4.28 & -0.23 & -4.63 & 0.73 \\
& $6 / 8$ & 34.46 & 4,28 & -0.35 & -4.63 & 0.69 \\
& $6 / 9$ & 36.79 & 4.29 & -0.27 & -4.66 & 0.6 \\
& $6 / 10$ & 39.38 & 4.28 & -0.22 & -4.67 & 0.56 \\
& $6 / 11$ & 41.72 & 4.28 & -0.32 & -4.63 & 0.69 \\
\hline \multirow{2}{*}{$(12.0)$} & $7 / 8$ & 36.97 & 4.28 & -0.19 & -4.69 & 0.53 \\
& $7 / 9$ & 39.33 & 4.29 & -0.16 & -4.69 & 0.53 \\
& $7 / 10$ & 41.84 & 4.28 & -0.24 & -4.69 & 0.52 \\
& $7 / 11$ & 44.23 & 4.28 & -0.19 & -4.69 & 0.51 \\
& $7 / 12$ & 46.67 & 4.29 & -0.13 & -4.69 & 0.51 \\
\hline \multirow{2}{*}{$(14.0)$} & $8 / 9$ & 41.75 & 4.28 & -0.22 & -4.64 & 0.6 \\
& $8 / 10$ & 44.28 & 4.27 & -0.16 & -4.66 & 0.53 \\
& $8 / 11$ & 46.68 & 4.28 & -0.18 & -4.63 & 0.61 \\
& $8 / 12$ & 49.12 & 4.28 & -0.21 & -4.67 & 0.56 \\
& $8 / 13$ & 51.59 & 4.27 & -0.15 & -4.69 & 0.43 \\
\hline \multirow{2}{*}{$(16.0)$} & $9 / 10$ & 46.75 & 4.28 & -0.04 & -4.69 & 0.57 \\
& $9 / 11$ & 49.16 & 4.28 & -0.12 & -4.67 & 0.62 \\
& $9 / 12$ & 51.6 & 4.29 & -0.07 & -4.68 & 0.58 \\
& $9 / 13$ & 54 & 4.28 & -0.03 & -4.7 & 0.43 \\
& $9 / 14$ & 56.53 & 4.28 & -0.1 & -4.68 & 0.59
\end{tabular}



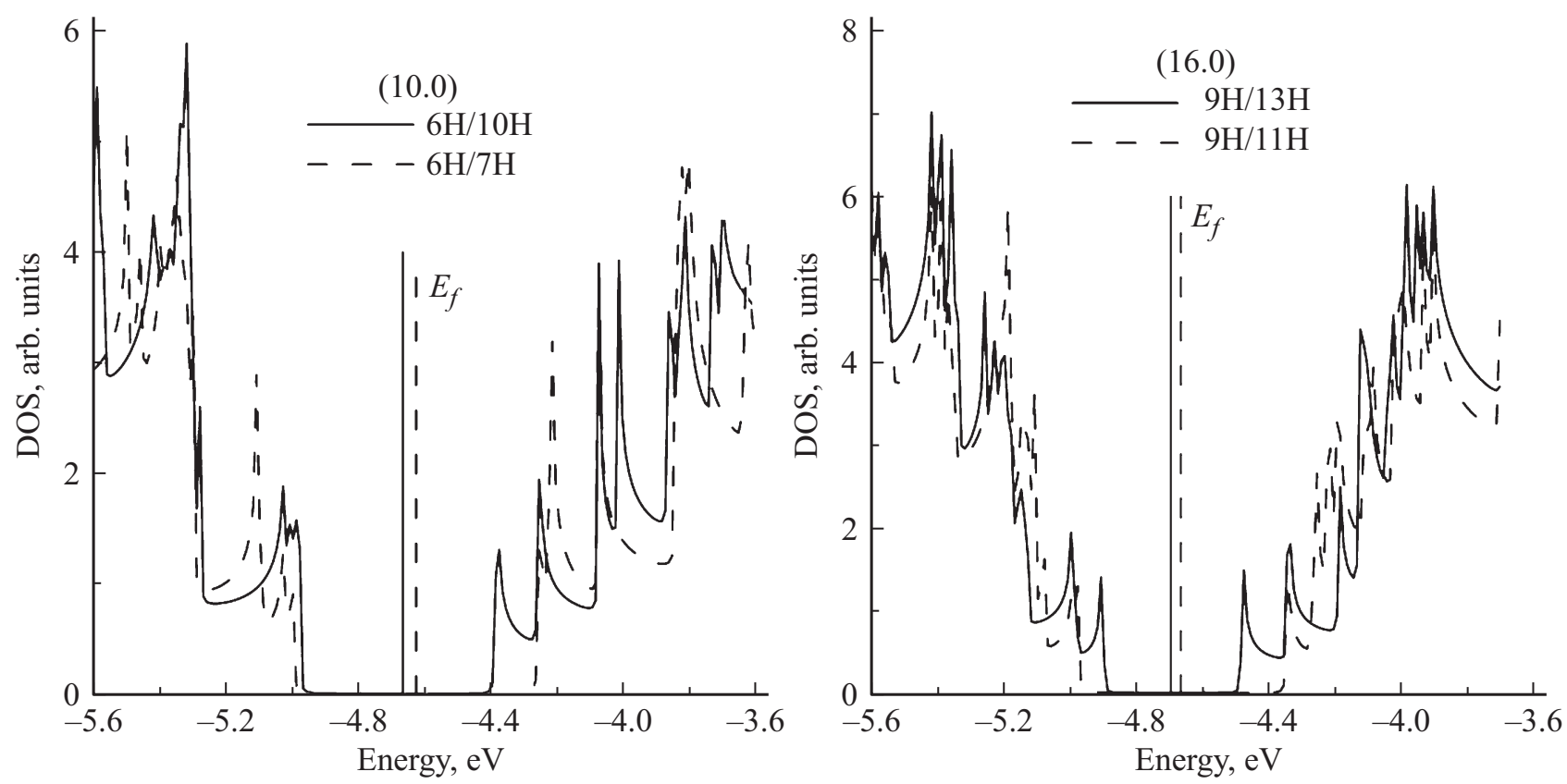

Pис. 5. Графики DOS для композитных пленок с наименьшей и наибольшей по диаметру трубками (10.0) и $(16.0)$.

нестабильности структуры или о ее метастабильном состоянии. Самой стабильной структурой, согласно нашим исследованиям, является пленка с трубкой (10.0) и с шагом расположения 6/8. Также к наиболее стабильным энергетически можно отнести все структуры с трубкой (10.0) с шагом 6/11 и 6/7. Также в таблице приведены векторы трансляции $L_{x}$ и $L_{y}$ полученных суперъячеек композитных пленок. У всех рассмотренных моделей вектор трансляции $L_{x}$ увеличивается на значения, лежащие в диапазоне $2.46 \pm 0.13 \AA$. Вектор трансляции $L_{y}$ практически не изменяется.

Методом SCC DFTB2 также была рассчитана плотность электронных состояний (DOS). Расчеты проводились в $s p$-базисе. На рис. 5 представлены графики DOS для композитных пленок с наименьшей и наибольшей по диаметру трубками (10.0) и (16.0). Для них показаны DOS с теми расстояниями $\mathrm{H}_{1} / \mathrm{H}_{2}$, которые характеризуются наименьшей и наибольшей энергетической щелью. Наименьшая щель для композитных пленок с (10.0) и (16.0) соответствует разным сочетаниям $\mathrm{H}_{1} / \mathrm{H}_{2}$, как и наибольшая. В таблице представлены рассчитанные значения уровня Ферми $E_{\mathrm{F}}$ и величины энергетической щели $E_{\text {gap }}$.

Из данных таблицы и рис. 5 можно увидеть, что уровень Ферми во всех случаях приблизительно одинаков $-4.70--4.63$ эВ. Щель присутствует в зонной структуре всех исследованных моделей пленок и составляет величину в интервале $0.41-0.73$ эВ, т.е. независимо от типа проводимости самой нанотрубки все композитные пленки являются полупроводниками. При этом ширина щели для композитных пленок с трубками (10.0) сужается и составляет величину в интервале 0.56-0.73 эВ относительно ширины щели индивидуаль- ных трубок (10.0), равную 0.9 эВ. Ширина щели для индивидуальных трубок (14.0) и (16.0) равна $\sim 0.57$ эВ, для композитных пленок с трубками (14.0) и (16.0) ширина щели изменяется в диапазонах $0.43-0.61$ эВ и 0.43-0.62 эВ соответственно. Для композитных пленок с трубками (12.0) ширина щели уширяется до интервала $0.51-0.53$ эВ относительно индивидуальных трубок (12.0), которые имеют металлический тип проводимости и ширину щели 0.07 эВ.

\section{3. Электропроводность}

С целью выявления закономерностей токопереноса были рассчитаны вольт-амперные характеристики для всех рассмотренных моделей композитных пленок графен/УНТ. При расчете токопереноса в структуре использовалась формула Ландауэра-Буттикера [11]:

$$
I=\frac{e}{\hbar} \int_{-\infty}^{\infty} T(E) d E\left[f_{1}(E)-f_{2}(E)\right]
$$

где $T(E)$ - функция пропускания, которая определяет суммарную квантово-механическую прозрачность проводящей структуры по всем независимым каналам проводимости для электрона, обладающего энергией $E ; f_{1}$ и $f_{2}$ - функции Ферми-Дирака, которые характеризуют энергетические уровни истока и стока, соответствующие уровню энергии проводящей структуры.

При расчетах вольт-амперных характеристик ток был направлен вдоль нанотрубок композитных пленок, так как в перпендикулярном направлении ток отсутствует. 

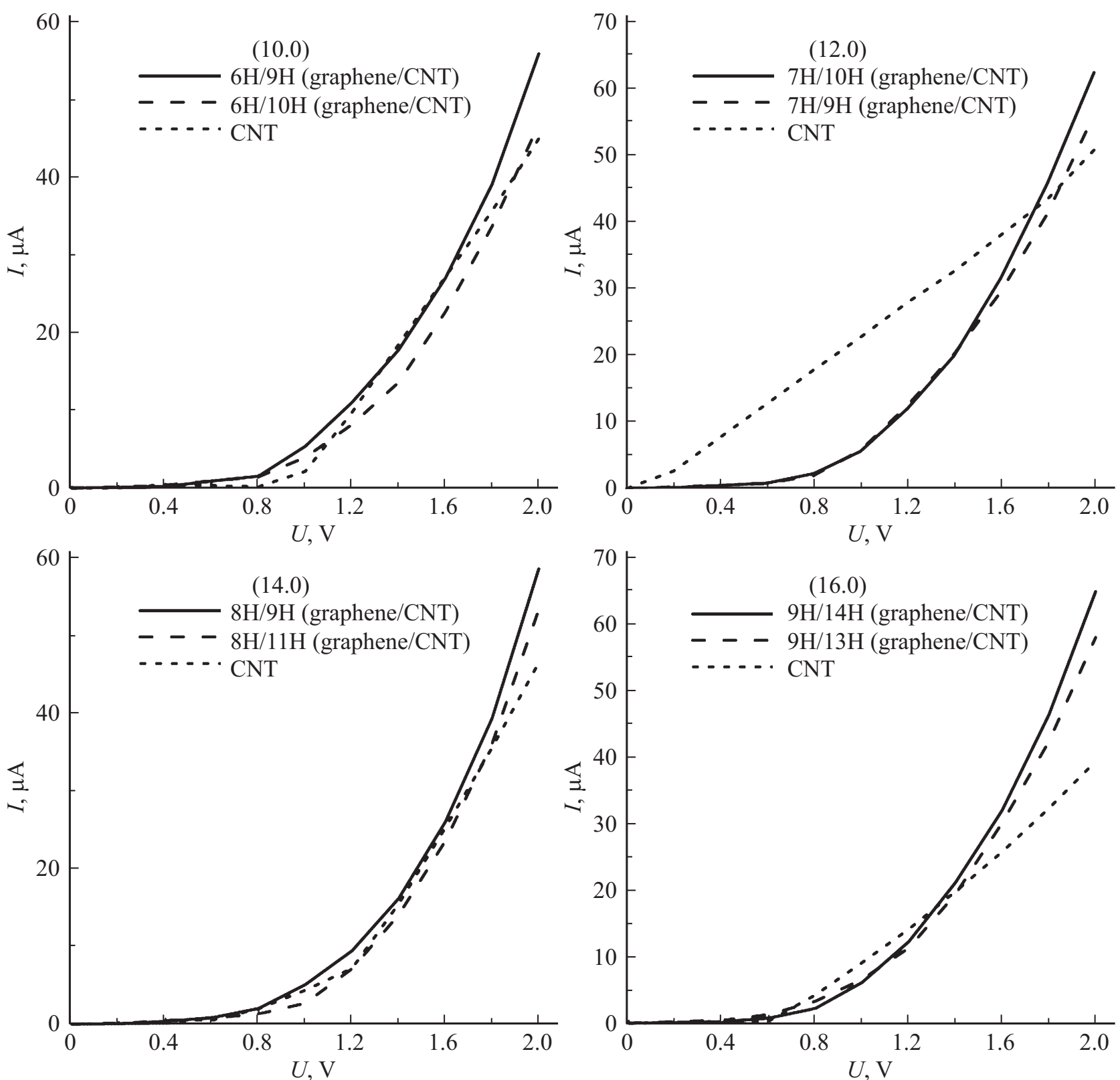

Рис. 6. Граничные кривые семейств вольт-амперных характеристик композитных пленок, которые отвечают моделям с минимальным $I_{\min }$ и максимальным $I_{\max }$ значениями тока при напряжении 2 В и вольт-амперные характеристики пленок из нанотрубок.

В результате расчетов были получены семейства вольтамперных характеристик. На рис. 6 приведены граничные кривые семейств вольт-амперных характеристик, которые отвечают моделям с минимальным $I_{\min }$ и максимальным $I_{\max }$ значениями тока при напряжении 2 В (шаг напряжения был взят $0.2 \mathrm{~B}$ ).

Для композитных пленок графен/УНТ с трубками $(10.0)-I_{\min }(6 \mathrm{H} / 10 \mathrm{H})=46.68$ мкA, $I_{\max }(6 \mathrm{H} / 9 \mathrm{H})=$ $=55.73$ мкА $\quad(12.0)-I_{\min }(7 \mathrm{H} / 9 \mathrm{H})=56.87$ мкA, $I_{\max }(7 \mathrm{H} / 10 \mathrm{H})=62.34 \mathrm{M \kappa A} ; \quad(14.0)-I_{\min }(8 \mathrm{H} / 11 \mathrm{H})=$ $=53.21 \mathrm{м \kappa A}, \quad I_{\max }(8 \mathrm{H} / 9 \mathrm{H})=58.45 \mathrm{M \kappa A} ; \quad(16.0) \quad-$ $I_{\min }(9 \mathrm{H} / 13 \mathrm{H})=57.83$ мкA, $I_{\max }(9 \mathrm{H} / 14 \mathrm{H})=64.72$ мкА. Для всех остальных моделей кривые вольт-амперных характеристик находятся в области между граничными кривыми. Также на рисунках показаны вольт-амперные характеристики пленок из соответствующих УНТ. Эти пленки представляют собой слой из нанотрубок, расположенных параллельно и нерегулярно относительно друг друга, на таких же расстояниях, как и в рассмотренных моделях композитных пленок. Кривые вольт-амперных характеристик пленок из УНТ ведут себя по-разному, в зависимости от типа проводимости нанотрубки. Вольт-амперные характеристики пленки из трубок (12.0) резко отличаются от других, поскольку трубка (12.0) характеризуется металлическим типом проводимости. Однако из сравнения всех полученных 
кривых вольт-амперных характеристик видно, что значения тока при напряжении 2В в композитных пленках больше, чем в пленках из нанотрубок.

\section{4. Заключение}

Построены топологические модели композитных пленок графен/УНТ с нерегулярным распределением трубок. Было установлено, что энергетически устойчивые соединения графен-УНТ с ковалентными связями могут образовывать только трубки типа zigzag (n.0) с четным числом $n$. Также было выявлено, что самой стабильной структурой является пленка с трубкой (10.0) и с шагом расположения $6 / 8$.

На основе анализа плотности электронных состояний сделан вывод, что композитные пленки графен/УНТ относятся к полупроводникам, поскольку большинство топологических моделей показывает ширину энергетической щели в интервале $0.41-0.73$ эВ.

Для построенных моделей композитных пленок были рассчитаны семейства вольт-амперных характеристик. Было показано, что значения тока при напряжении 2 В в композитных пленках больше по сравнению с пленками из нанотрубок.

В итоге можно заключить, что композитные пленки графен/УНТ могут стать основой для элементной базы полупроводниковых приборов. Для этого композитные пленки обладают, судя по теоретическому прогнозу, всеми необходимыми качествами.

\section{Финансирование работы}

Работа выполнена при поддержке Российского фонда фундаментальных исследований (грант № 18-32-01003) и гранта Президента Российской Федерации для государственной поддержки научных исследований молодых российских ученых МК-2373.2019.2.

\section{Конфликт интересов}

Авторы заявляют, что у них нет конфликта интересов.

\section{Список литературы}

[1] Z. Yan, Z. Peng, G. Casillas, J. Lin, C. Xiang, H. Zhou, Y. Yang, G. Ruan, A.-R.O. Raji, E.L.G. Samuel, R.H. Hauge, M.J. Yacaman, J.M. Tour. ACS Nano, 8 (5), 5061 (2014).

[2] S.H. Kim, W. Song, M.W. Jung, M.-A. Kang, K. Kim, S.-J. Chang, S.S. Lee, J. Lim, J. Hwang, S. Myung, K.-S. An. Adv. Mater., 26 (25), 4242 (2014).

[3] V.C. Tung, L.M. Chen, M.J. Allen, J.K. Wassei, K. Nelson, R.B. Kaner, Y. Yang. Nano Lett., 9, 1949 (2009).

[4] J. Li, J. Tang, J. Yuan, K. Zhang, X. Yu, Y. Sun, H. Zhang, L.-C. Qin. Chem. Phys. Lett., 693, 60 (2018).

[5] W. Yang, Y. Chen, J. Wang, T. Peng, J. Xu, B. Yang, K. Tang. Nanoscale Res. Lett., 13, 181 (2018).
[6] Y. Liu, F. Wang, X. Wang, X. Wang, E. Flahaut, X. Liu, Y. Li, X. Wang, Y. Xu, Y. Shi, R. Zhang. Nature Commun., 6, 8589 (2015).

[7] V.V. Mitrofanov, M.M. Slepchenkov, Gang Zhang, O.E. Glukhova. Carbon, 115, 803 (2017).

[8] M. Elstner, D. Porezag, G. Jungnickel, J. Elsner, M. Haugk, Th. Frauenheim, S. Suhai, G. Seifert. Phys. Rev. B, 58, 7260 (1998).

[9] M. Elstner, G. Seifert. Phil. Trans. R. Soc. A, 372, 20120483 (2014).

[10] X. Cui, R. Lv, R.U.R. Sagar, C. Liu, Z. Zhang. Electrochim. Acta, 169, 342 (2015).

[11] Y. Meir, S. Wingreen. Phys. Rev. Lett., 68, 2512 (1992).

Редактор Г.А. Оганесян

\section{Current-voltage characteristics of composite graphene-nanotube films with irregular arrangement of nanotubes}

\author{
O.E. Glukhova, M.M. Slepchenkov, \\ V.V. Mitrofanov, P.V. Barkov
}

Saratov State University, 410012 Saratov, Russia

\begin{abstract}
Topological models of the graphene/CNT hybrid composite have been constructed, which are tubes that lie irregularly between graphene monolayers and parallel to them, covalently linked to graphene. The distance between the tubes was measured in hexagons $\left(\mathrm{H}_{1}\right.$ and $\left.\mathrm{H}_{2}\right)$ of graphene between the ribs involved in the formation of covalent bonds. It was shown that only those films that are based on zigzag (n.0) tubes with an even number $n$ are energetically stable. According to our research, the most stable structure is a film with a tube (10.0) and with an arrangement step of $6 / 8$. It was found that the energy gap is present in the band structure of all the studied film models and is in the range of $0.41-0.73 \mathrm{eV}$.
\end{abstract}

